\title{
Factors that Influence Modern Contraceptive use Among Women Aged 35 - 49 Years and their Male Partners in Gomoa West District, Ghana: A Qualitative Study
}

\author{
Amy Takyi \\ Nagasaki University School of Tropical Medicine and Global Health \\ Miho Sato \\ Nagasaki University School of Tropical Medicine and Global Health \\ Michael Adjabeng \\ World Health Organization (WHO) Country Office Accra \\ Chris Smith ( $\nabla$ christopher.smith@lshtm.ac.uk) \\ Nagasaki University School of Tropical Medicine and Global Health
}

\section{Research Article}

Keywords: Family planning, contraception, male partner, Ghana

Posted Date: November 29th, 2021

DOI: https://doi.org/10.21203/rs.3.rs-1103240/v1

License: (c) (1) This work is licensed under a Creative Commons Attribution 4.0 International License.

Read Full License 


\section{Abstract}

Background: The use of contraception among women aged 35 to 49 years is imperative due to the risk of unplanned pregnancy and poor obstetric outcomes. However, the use of contraceptives in this age group has been reported to be low. In Ghana, studies are limited that determine factors influencing contraception among women in this age group, in particular the influence of husbands. This study aims to ascertain factors that influence contraception among women aged 35 to 49 years and their male partners.

Objectives: The objective of the study was to describe factors that influence modern contraceptive use among women aged 35 to 49 years and their male partners in the Gomoa West District of Ghana. Methods: A total of 44 informants participated in the study. In-depth interviews were conducted remotely for 22 women, 15 male partners of women interviewed, and seven family planning service providers. Twenty-one informants participated in four focus group discussions organized. A simple thematic analysis was undertaken.

Results: Factors that influenced the use of modern contraceptives were achieved desired family size, counselling by health professionals, health reasons, and influence of male partner. Barriers to using modern contraceptives included religious or socio-cultural reasons, experience or fear of side effects, rumors or misconceptions, and the belief that contraceptive use is a matter for women.

Conclusions: This study described factors that influence contraception among women 35 to 49 years and their male partners. All informants used some form of contraception, although traditional contraceptive method users (TCMUs) did not consider traditional contraceptive methods (TCMs) as a form of contraception. Education on effective TCMs as an alternative for non-users of modern contraceptive methods (MCMs) is needed. Strengthening male involvement in family planning and health educational activities could alleviate fear and reduce misconceptions about using modern contraceptives.

\section{Plain English Summary}

Women aged 35 to 49 years are considered vulnerable to unplanned pregnancy, which could have undesirable consequences. For this reason, contraceptive use is essential. Male partners have some influence on the decisions women make on contraception. This study aimed to describe factors that influence modern contraceptive use among women aged 35 to 49 years and their male partners in Gomoa West District, Ghana.Our study conducted 44 in-depth interviews among 22 women aged 35 to 49 years, 15 male partners of women interviewed, and seven family planning service providers. We also organized four focus group discussions for 21 informants who had participated in the interviews. We recorded the interviews and focus group discussions, transcribed and analyzed them to identify the main themes with permission. We found that achieved desired family size, counselling by health professionals, health reasons, and influence of male partners promoted the use of modern contraceptives. However, participants reported that religious or socio-cultural reasons, experience or fear of side effects, rumors or 
misconceptions about modern contraception, and the viewpoint that contraceptive use is a matter for women were reasons why some participants did not use modern contraception. In conclusion, all the participants used some form of contraception because they recognized their high vulnerability to an unplanned pregnancy. However, women who used TCMs did not see it as a form of contraception. Providing health education on effective TCMs is important. We recommend that encouraging couple participation in family planning and health educational activitiescan correct some misunderstandings about modern contraceptives.

\section{Background}

Contraception enables individuals and families to control fertility by reducing unintended pregnancy, abortions, and pregnancy-related morbidity and death (WHO, 2014). The use of contraception among women aged above 35 years has been reported to be low in low- and middle-income countries (LMICs) [1]. The low utilization of contraceptives and the use of less effective contraceptive methods have resulted in unplanned pregnancy among women in this age group in sub-Saharan Africa and was reported to be highest among women aged 40 to 44 years [2]. Some undesirable consequences of pregnancies among women above 35 years include preeclampsia, placenta abruption, and placenta previa, which increased significantly with age [3]. Additionally, advanced maternal age is a risk factor for spontaneous miscarriage; reported to be $50 \%$ and $75 \%$ among women age 42 years and 45 years, respectively. Moreover, advanced maternal age negatively affects neonatal outcomes such as small gestational age, fetal distress, and stillbirth [4].

Contraception among women aged over 35 years is important due to the risk of unplanned pregnancy and poor obstetric outcomes. Even though the use of contraception increased globally from $42 \%$ in 1990 to $49 \%$ in 2019 [5], the contraceptive prevalence rate has been low in sub-Saharan Africa, especially in Central and West Africa [5]. The type of contraception used varies according to the age of women [6].

It has been reported that short-acting and traditional contraceptive methods (TCMs) are commonly used among women who want to limit childbearing, older, and married women in sub-Sharan Africa compared with long-acting reversible contraceptive methods, which are more effective and have a long duration of protection and low failure rate [7]. The use of TCMs among older women could be due to a low perception of pregnancy, unstable relationships, and infrequent sexual activity. Moreover, desire for more children, fear of side effects, and poor access to modern contraceptives could influence the use of TCMs [8,9]. Among married women, the influence of husbands was identified as an important factor in the use and non-use of modern contraceptives among women in Ghana [10]. The peculiar characteristics of women in the 35 to 49 age group make it essentialto engage their male partners to understand the vulnerability and risks of their wives to poor maternal outcomes and the importance of using modern contraceptives to prevent unintended pregnancy. Even though the knowledge on contraception is high (more than 96\%) in Ghana, the use of contraceptives decreases with age, and the proportion of unwanted pregnancy ishighest among women aged $45-49$ years[11]. Whereas factors influencing contraceptive use among women aged $15-49$ years have been reported by several quantitative studies[12,13,14], there is a 
scarcity of information to understand the factors that influence contraceptive use among women aged 35 - 49 years and their male partners. This article aims to examine barriers and factors that promote modern contraceptive use among women 35 to 49 years and their male partners.

\section{Methods}

The qualitative study was conducted to understand and describe the experiences of women aged $35-49$ years and their male partners about the use and non-use of modern contraception in Gomoa WestDistrict, located in the Central region of Ghana. Gomoa West has received support from the USAID to improve family planning coverage over the years. However, the uptake of contraception has fluctuated in recent years $(20 \%, 22 \%$, and $20 \%)$ from the year 2018 to 2020 , respectively, as reported in the annual reports of the district. Apam and Oguaa sub-districts were selected within the district because they are the largest communities along the urban coastal and rural farming communities where participants with diverse socio-demographic and economic backgrounds could be purposefully identified.

The Ghana Statistical Service estimated the district population to be 135,189 according to the 2010 population census, with $45 \%$ males and $55 \%$ females. More than half $(57 \%)$ of the population reside in rural areas. Most residents are of the Fanti ethnic group. However, there are small settlements of Ewes, Gas, and other ethnic groups along the coast engaged in the fishing industry.

The study adopted the inclusion criteria developed by Westoff and Ochoa (1991) to guide the selection of informants [15]. Inclusion criteria were women aged 35 to 49 years who were currently married or in a sexual union and using or not using modern contraceptives, not pregnant, had lived in the District for at least one year, or a family planning service provider who had worked in a public health facility within the District for at least one year. Male partners were recruited after permission was obtained from women who had already participated in the interview. It was considered important to explore the perspective of the men on contraception because of the influence they have on the uptake of contraceptivesamong women $[10,15,16,17]$.

Semi-structured in-depth interviews (IDIs) were conducted remotely for 22 women aged 35 to 49 years, 15 male partners of women interviewed, and seven family planning (FP) providers. Informants were selected purposively to consider participants from urban and rural communities who were users and non-users of modern contraceptive methods with diverse socio-cultural backgrounds. Overall, 44 informants participated in the IDIs.

Additionally, four FDGs were organized for women aged 35 to 49 years and their male partners who were users and non-users of MCMs in rural and urban communities to observe a common opinion of informants about contraception.

The IDI topic guide was developed separately for women aged 35 - 49 years, male partners and family planning providers. The topic guide included topics on knowledge, perception, and utilization of contraceptives, motivators and barriers to using modern contraceptive methods, perception of male 
partners about contraception, and the influence of male partners on contraceptive use. The FGD topic guide had open-ended prompts which covered topics on their experiences of using contraceptives (MCMs and TCMs), reasons for non-use of MCMs, and the influence of the male partner on contraception. The topic guides used in this study are shownin Table 1.

\section{Table 1: Interview topic guide}

\section{Knowledge, perception and use of contraceptives \\ I. A re you currently using a contraceptive? \\ II. What was your experience in using contraception? \\ III. What informed the decision to use contraception?}

\section{Barriers to contraceptives use}

I. Tell me about any experienced of side effect using contraception? Probe

II. What are some of the rumors you hear about modem contraceptives?

III. What do you think are the reasons why other women within this age group (3549 years) may use modem contraceptives?

a. Why will others not use modem contraceptive method

\section{Factors that promote contraceptive use}

I. What benefits does a woman get from using contraceptives?

II. What can the health service do to promote the use of contraceptive among women over 35 years?

III. What role do you think the community can do to promote the use of contraceptives?

\section{Perception of women about contraception among male partners}

I. Is your male partner aware using contraception?

II. What do you think about your male partner using contraceptive?

III. Not using contraception.

IV. Is there anything else you think I should know about contraceptives use and nonuser among these women and their male partner in your community?

\section{Perception of male partners about contraceptives}

I. Is your partner using contraception?

II. What do you think about your male partner using contraceptive?

III. Not using contraception.

IV. Is there anything else you think I should know about contraceptives use and nonuser among these women and their male partner in your community?

V. Is there anything else you think I should know about contraceptives use and nonuser among these women and their male partner in your community?

\section{Male partner influence on contraceptives use}

I. What role do you think male partners play in:

a. The use of contraceptives among women?

b. Non-use of modern contraceptives?

II. Is there anything you would like to share with me? 
The research assistants who had tertiary education in community health and public nursing were trained virtually through Zoom for two days. Day one was used to explain the research rationale, ethical considerations, and data collection tools. On day two, the data collection tools were revised and modified to reflect the feedback received after pretesting in a neighboring district.

Informants who used modern contraceptive methods (MCMs) were selected from FP clinics of two health centers. Non-users of modern contraceptives were identified and contacted face to face through home visits by research assistants with community health nurses and community health volunteers. Using the staff list from the district, the research team worked with the seven sub-district heads to select the seven FP providers who were public health nurses, general nurses, and community health nurses. Twenty-one informants with diverse backgrounds who were interviewed consented to participate in four FGDs for users and non-users of MCMs facilitated by the principal investigator (PI) with the support of three research assistants.

The IDIs and FGDs were conducted in English or the local Fante language if preferred by the informant; audio recorded with permission, in the house of the informants for IDIs or school compound and health facility for FGDs. IDIs and FGDs were conducted from $1^{\text {st }}$ to $22^{\text {nd }}$ February 2021. There were seven refusals; four women (two users and two non-users) did not permit the research team to interview their husbands. The reasons were that the husbands were not aware that the informant used MCMs, others presumed that their husbands would not be interested in the interview, and some were unwilling to provide phone numbers of their male partners who had travelled. Three husbands declined to be interviewed due to their busy schedules.

Eighteen informants were contacted twice to obtain more information.

Key ethical issues were explained to all participants prior to data collection. Informants participated by signing or thumb printing the informed consent form as evidence of their voluntary participation. The study adopted the inclusion and exclusion criteria developed byWestoff and Ochoa (1991)[15].

The procedure for the remote data collection was explained. Informants who preferred to use their mobile phones for the remote interview were given a ten Ghana Cedis (GHC 10.00) [US\$1.68] recharge card. However, informants who did not have the WhatsApp application on their mobile phone or those who preferred to use the mobile phone purchased for the research assistants for data collection were given access. After the informant was taken through the information sheet and informed consent form, a research assistant connected the PI via the WhatsApp application.

Due to the remote nature of the study, research assistants were trained to keep field notes to capture nonverbal communication and other observations. The PI also kept fieldnotes and discussed them with the research assistants after each interview. The PI asked further probing questions after reflecting on the responses from the informants to clarify any ambiguity and ensure accuracy and consistency in data collection. The average duration of interviews among women and their husbands was 55 minutes and 58 minutes among FP providers. The FGDs lasted for an average duration of 96 minutes. 
Data saturation was reached between informants between 39 to 44. The PI worked at Gomoa West District Health Directorate and is familiar with the study area. The PI examined her values, assumptions, and prior understanding brought into the study to reduce bias throughout the research period. The PI also kept a field note to document her thoughts and observations during the research process [12].

Data were transcribed from the local Fante language to English by the PI. Data analysis was flexible, iterative, and simultaneously during data collection. A thematic analysis by Braun and Clarke (2006) was adopted to identify, analyze, and report patterns within the data collected [20]. Coding was done on two levels. First, inductive coding was done by using in vivo and descriptive coding. This approach gives a complete picture of the themes which emerged from the data. Secondly, to answer the research questions, deductive coding was undertakenbased on the research objectives and the conceptual framework of Hall (2012) with modifications bringing in the constructs of the health belief model to study factors that influence the attitudes and practice of contraception [21] (Figure 1).

Reference: Adapted from(Hall, 2012).

AT transcribed the data, read the interview transcripts and field notes several times to be conversant with the data collected, coded the data, and identified the main themes. MS, MA, and CS reviewed the themes identified. Data were managed using Nvivo12 qualitative analysis software.

Patterns of similarities and differences were identified from the codes generated, which were put into subcategories, categories, and themes. The themes identified were examined, renamed, and merged to reflect the research objectives. The codes and categories under each theme were examined to ensure that they were descriptive of the themes.

Informants were assured of privacy and confidentiality of the information they provided. Pseudonyms were used to store participants' information. All informant responses reported during the findings of the study were disguised to ensure anonymity without distorting the data content. All soft copies of the informant's information, interview transcripts, field notes, and audio recordings were stored on the PI's personal computer protected by a password, backed up on a password-protected external hard drive, and kept in a secure locker. Some quotations of informants were extracted as evidence of response. Ethical approval was obtained from Nagasaki University (Ref: NU_TMGH_2020-146-1) and Ghana Health Service Ethics Review Committees (Ref: GHS-ECR028/11/20).

\section{Results}

The socio-demographic characteristics of informants are summarized in Table 2. The median age of women was 38.5 years. All 15 male partners of the women interviewed were older than their female partners. Christianity was the most common religion among all informants. Most (57\%) of the FP providers were community health nurses with a median age of 31 years. Injectables were the most commonly used MCMs, whereas periodic abstinence was prevalent among traditional contraceptive users. Five male partners had ever used a male condom, but only two were current users. 


\section{Table 2. Socio-demographic characteristics of the informants}




\begin{tabular}{|c|c|c|c|c|}
\hline Characteristics & Women & $\begin{array}{l}\text { Male } \\
\text { partner }\end{array}$ & $\begin{array}{l}\text { FP } \\
\text { providers }\end{array}$ & Total \\
\hline Age group (years) & $N=22$ & $N=15$ & $N=7$ & $\begin{array}{l}N= \\
44\end{array}$ \\
\hline $25-29$ & 0 & 0 & 3 & 3 \\
\hline $30-34$ & 0 & 0 & 3 & 3 \\
\hline $35-39$ & 12 & 2 & 1 & 15 \\
\hline $40-44$ & 6 & 6 & 0 & 12 \\
\hline $45-49$ & 4 & 6 & 0 & 10 \\
\hline Above 50 & 0 & 1 & 0 & 1 \\
\hline Educational level & $N=22$ & $N=15$ & $N=7$ & $\begin{array}{l}N= \\
44\end{array}$ \\
\hline No education & 2 & 0 & 0 & 2 \\
\hline Primary & 5 & 0 & 0 & 5 \\
\hline Secondary & 8 & 6 & 0 & 14 \\
\hline Tertiary & 7 & 9 & 7 & 23 \\
\hline Religion & $N=22$ & $N=15$ & $N=7$ & $\begin{array}{l}N= \\
44\end{array}$ \\
\hline Christianity & 21 & 14 & 6 & 41 \\
\hline Muslim & 1 & 1 & 1 & 3 \\
\hline Occupation & $N=22$ & $N=15$ & $N=7$ & $\begin{array}{l}N= \\
44\end{array}$ \\
\hline Government worker & 6 & 8 & 7 & 21 \\
\hline Self employed & 13 & 7 & 0 & 20 \\
\hline Homemaker & 3 & 0 & 0 & 3 \\
\hline $\begin{array}{l}\text { Type of modern contraceptives used - users (current \& } \\
\text { previous users) }\end{array}$ & $\mathrm{N}=22^{\mathrm{a}}$ & $N=15^{b}$ & NA & $\begin{array}{l}N= \\
27\end{array}$ \\
\hline Injectables & 14 & NA & NA & 14 \\
\hline Pills & 5 & NA & NA & 5 \\
\hline Implants & 2 & NA & NA & 2 \\
\hline IUD & 1 & NA & NA & 1 \\
\hline
\end{tabular}




\begin{tabular}{|c|c|c|c|c|}
\hline Male condom & NA & 5 & NA & 5 \\
\hline $\begin{array}{l}\text { Type of Traditional contraceptive method used among } \\
\text { TCMUs }\end{array}$ & $N=11^{c}$ & $N=8^{d}$ & NA & $\begin{array}{l}N= \\
19\end{array}$ \\
\hline Period abstinence method & 11 & 2 & NA & 11 \\
\hline Withdrawal & NA & 1 & NA & 11 \\
\hline \multicolumn{5}{|l|}{${ }^{a}$ Frequency of MCMs used among all women } \\
\hline \multicolumn{5}{|l|}{${ }^{b}$ Frequency of MCMs used among all male partners } \\
\hline \multicolumn{5}{|l|}{${ }^{\mathrm{C}}$ Type of TCMs used among TCMUs women } \\
\hline${ }^{d}$ Type of TCM used among male partners of TCMUs & & & & \\
\hline
\end{tabular}

It was revealed during the IDIs that almost all non-users of modern contraceptive methods used traditional contraception, which was not considered a form of contraception by the informants. One informant did not use any form of contraception because of her plan to get pregnant. In the study,the term MCM was used equivalent to contraception among informants.T wo major themes were identified: facilitators of contraceptive use and barriers to contraceptive use.

\section{Factors that promote the use of modern contraceptives}

This theme describes the factors that promoted the use of moderncontraception, such as achieved desired family size, counselling by health staff, health reasons, andinfluence of the male partner.

Seven informants who used MCMs indicated that they had achieved the desired family size.

"After given birth to four children, I decided to do the five years family planning [Jadelle $囚$ ], so when I got to the clinic, I told them what I wanted to do." (MCMU 3).

Two women who were users of TCM expressed their intention to use MCMs after giving birth to the number of children they desire.

"When I give birth to the 5 children I desire, then I will do family planning to prevent any unplanned pregnancy." (TCMU 2)

Among seven couples there were conflicting views on the achievement of the desired family size. Four husbands indicated that they had achieved the desired family size; however, their wives wanted to have one or two more children.

Five informants mentioned that counselling and health education by health workers encouraged them to use MCMs. A mother of five children on her experience with health workers' advice to use MCMs stated 
that:

"For me, if they [the doctors] had not told me to come and do it, I wouldn't have done family planning." (MCMU 5).

Some informants mentioned that pregnancy at an advanced maternal age was dangerous. A couple agreed on female sterilization after their $5^{\text {th }}$ children because of perceived risk to poor maternal outcomes in subsequent pregnancies.

"When my wife gave birth to the $5^{\text {th }}$ child, she bled profusely. I was worried about her life and health if she gets pregnant again. So, we agreed and the doctors did the sterilization for her." (HMCMU 6)

Husbands played a significant role in choosing and using MCMs. Eight male partners confirmed this. After making a joint decision to plan their family, a husband of an informant accompanied her to buy the pills at a drug store as she was shy because it was her first time using an MCM. However, among TCM users, two informants were discouraged by their husbands from using modern contraceptives because of the fear of side effects.

"I will not recommend women to use the modern contraceptives. During their unsafe period, their husbands can abstain from sex or use the male condom." (HTCMU 6)

\section{Barriers to modern contraceptives use}

This theme describes factors that were perceived to hinder modern contraceptive use, such as religious or socio-cultural reasons, experience or fear of side effects, rumor or misconceptions, and the belief that contraceptive use is a matter for women.

Socio-cultural factors were prominent among men as reasons for the non-use of male condoms. Eight male partners mentioned that using a male condom was a common practice among unmarried young men who engaged in premarital sex. Married men who used male condoms were seen as promiscuous.

"Most of the community members think that a married man should not use male condom, it is the young men who are not married who should use it. When they see a married man going to buy it, they think that he is cheating on his wife." (HTCMU 5).

The FP providers stated that the activities of some Pastors discouraged women from using MCMs.

"There is a Pastor in community $X$, who tells his congregation not to do family planning, so most of the women there do not do it. Others hide and come for family planning." (FPP 3).

The experience and fear of side effects prevented five women and two husbands from using MCMs. Seven informants had experienced some side effects. Most (five out of seven) of these informants used Depo Provera. 
"Some of us have used family planning before but we have to stop because of the side effects." (TCMU 8,).

Five informants had never used MCMs because of the side effects their friends and relatives experienced. Two male informants using male condoms discontinued because of the reaction of their wives. Additionally, a 41-year-old husband stopped using male condoms when he experienced side effects.

The fear of side effects caused by MCMs influenced the choice for TCMs among five informants. Three informants switched from MCM to TCM usage due to MCM side effects.

"When I started experiencing irregular menses and heart palpitations, I thought that it was time to stop using contraception before I encounter something worse." (TCMU 1)

In contrast, a 46-year-old mother of five children had not experienced any side effects after using Norigynon, monthly injectables, for five years.

Five out of seven family planning providers indicated that rumors/misconception was a primary concern that prevented the target group from accessing MCMs.

"Some also says they do not have their menses so the blood stay in their uterus which causes fibroid." (TMCU 3,).

Four male partners indicated that they considered family planning a woman's issue and did not encourage men to use male condoms. Not all men disapproved of the use of male condoms. For example, two male partners encouraged men to use male condoms because they considered them effective and without side effects.

"When I hear of the side effects of contraceptives, I think men should be encouraged to use the male condom to protect their wives from unplanned pregnancy." (HTCMU 10).

\section{Discussion}

\section{Summary of main results}

The study reported having achieved desired family size, counselling by health professionals, health reasons, the influence of male partner promoted modern contraceptive use among women 35 to 49 years and their male partners. The barriers included religious/socio-cultural reasons, experience/fear of side effects, rumour/misconceptions, and contraceptive use is a matter for women.

\section{Interpretation \& comparison with existing literature}

The findings that having achieved desired family size, counselling by health professionals, health reasons and influence of male partner promoted modern contraceptive use among women 35 to 49 years and their male partners are consistent with what has been found by studies among couples and married 
women in the 15 to 49 years age group in Ghana [12], Nigeria [3,14] and Kenya [15].Due to the perception that the use of MCMs causes infertility and adverse neonatal outcomes, some couples preferred TCMs to space pregnancy and limit birth. Others intend to switch to MCMs after they have achieved the desired family size.Among married men, approval from their wives enabled them to use male condoms to prevent unplanned pregnancy, particularly among TCM users. Building consensus on the use of male contraceptives is important because of the perception that married men who use male condoms are promiscuous.

Health professionals embody external cues that promote acting on using contraceptives. The activities of health professionals created opportunities to engage male partners, address health concerns, correct misconceptions, and provide accurate information about MCMs. This finding is corroborated by studies conducted in Ghana $[17,18,12]$ and in other parts of sub-Saharan Africa $[19,20,21,22,23]$.

Religious beliefs have been explored as one of the determinants of modern contraceptive use $[10,18,19$, 20]. In this study, religious beliefs were identified as a major barrier to contraception among married men more than married women. Among married men, the use of male condoms was perceived by some as a sin, which is against their religious beliefs. However, among married women who were Catholics and Muslims, religious beliefs did not prevent them from using MCMs even though FP providers stated that some religious leaders in the communities discouraged women from using MCMs. These participants explained that it was against their faith to have a large family and not provide for them. This perception may have influenced the low utilization of male condoms among married men.Male partners were more open and forthcoming with responses during the IDIs. Socially, the topic ofmale condoms among married men is considered sensitive, which may have influenced their responses during the FGDs. This result resonates with a study conducted in Ghana [10], which reported both positive and negative influences of religion on contraceptive use. The negative influence of religion is in line with studies from research in Ghana [24], Ethiopia [25], and Nigeria [26].

A major concern of using MCMs is side effects, as has been established by several studies conducted in LMICs and sub-Saharan Africa $[12,14,28]$.The experience of side effects resulted in discontinuation of MCMs, switching between MCMs,or shifting to TCMs. Moreover, the fear of side effects as a result of the experiences of friends or close relatives was the reason for the non-use of MCMs, as reported by studies in Ghana $[29,30,31,32,10]$. The reported side effects were headaches,dizziness, heart palpitations,and irregular ceased or excessive menstruation. Most of the MCMs users were informed of potential side effects.

The roles of rumor/misconceptions are described in the literature as a typical barrier to using modern contraceptives. Findings from this study showed that, among married women, myths and misconceptions about MCMs influenced their attitude and use of MCMs. The sources of misconceptions stem from herbal drug peddlers, previous users of MCMs, and community members. Currently, the use of herbal medicines in Ghana has gained popularity, reaching people through television, radio advertisements, and word of mouth. Dali et al. reported that in Ghana, some herbal medicines are used as 
contraceptives and to cause abortion [33]. As indicated by Kleinman's explanatory model, popular and folk sectors co-exist in society as alternatives to the professional health sector for providing health care [34]. Improvement in the level of education among women could promote a better understanding of MCMs and reduce misconceptions towards MCMs.

Male partners view contraceptives as an issue for females. Most married men support their wives' use of MCMs. However, due to the experience or fear of side effects and health concerns, some husbands use male condoms to protect their wives from unintended pregnancy, especially among couples who use TCMs. Moreover, men view that FP programs target women only; hence their involvement is low. Other studies also reflect such male perspectives of FP programs $[35,36,17]$.

\section{Strengths \& limitations}

A strength of this study is the triangulation of information by interviewing the male partners of women and FP providers. This provided the opportunity to obtain the perspectives of male partners on contraception, their influence on the use and non-use of MCMs among women, which is the unique strength of this study. Additionally, FGDs were conducted to observe a common view of informants about contraception.

This study has several limitations. The qualitative methodology used limits the generalization of the findings. The remote nature of the study reduced the opportunity for the PI to observe non-verbal communications by informants all the time continuously. The participation of male partners was at the discretion of the women interviewed. While this approach allowed us to triangulate the information, it limited male partner involvement in the study.

\section{Conclusions}

All women used some form of contraceptive due to a heightened perception of their susceptibility to pregnancy. However, most TCMUs in the study area did not consider the method as a form of contraception since MCM was synonymous with contraception. There is a need for family planning providers to provide education on effective TCMs, switching between MCMs, and potential side effects to prevent discontinuity and unplanned pregnancies.

Additionally, the male partner plays a significant role in the decisions women make on contraception. Engaging men on the importance and benefits of family planning could improve their support for modern contraceptives among women. Our study proposes thatthe District Health Directorate, in collaboration with the Local Government Authority and other stakeholders, could regulate the activities of herbal drug sellers who discourage women from using modern contraceptives.

\section{Abbreviations}

LMICs Low- and Middle - Income Countries. 
FP Family Planning.

FGD Focus Group Discussion

HTCMU Husband of Traditional Contraceptive Method User

MCM Modern Contraceptive Method

MCMU Modern Contraceptive Method User

PI Principal Investigator

TCM Traditional Contraceptive Method

TCMU Traditional Contraceptive Method User

USAID United States Agency for International Development

\section{Declarations}

\section{Ethics approval and consent to participate}

Ethical approval for this study was obtained from ethics committees at Nagasaki University (Ref:

NU_TMGH_2020-146-1) and the Ghana Health Service Ethics Review Committee (Ref: GHS-

ECR028/11/20). Informants were given an information sheet to read, or it was read to them and signed or thumb-printed consent in the presence of a witness.

\section{Consent for publication}

As part of the consent form, participants were informed that 'We will not write your name on this paper. You will be identified by an ID (alias). The informants gave consent for the findings of the study to be published.

\section{Availability of data and materials}

The transcripts from which this manuscript was developed are available and can be obtained on request from the corresponding author.

\section{Competing interests}

The authors declare that they have no competing interests.

\section{Funding}

Financial assistance to conduct this study was provided by Nagasaki University, School of Tropical Medicine and Global Health. 


\section{Authors' contributions}

AT, CS and MS designedthe study. MA coordinated data collection in Ghana, AT conducted the in-depth interviews and FGDs, analyzed the data, and drafted the manuscript. CS and MS reviewed the manuscript. All authors read and approved the final manuscript.

\section{Acknowledgments}

We thank staff at the Gomoa West District Health Directorate, the research assistants and informants who participated in the study.

\section{References}

1. Vu LTH, Oh J, Bui QTT, Le ATK. Use of modern contraceptives among married women in Vietnam: A multilevel analysis using the Multiple Indicator Cluster Survey (2011) and the Vietnam Population and Housing Census (2009). Glob Health Action. 2016;9(1):1-7.

2. Ameyaw EK, Budu E, Sambah F, Baatiema L, Appiah F, Seidu AA, et al. Prevalence and determinants of unintended pregnancy in sub-Saharan Africa: A multi-country analysis of demographic and health surveys. PLoS One. 2019;14(8):1-16.

3. Blomberg M, Tyrberg RB, Kjølhede P. Impact of maternal age on obstetric and neonatal outcome with emphasis on primiparous adolescents and older women: a Swedish Medical Birth Register Study. 2014;

4. Cohain JS, Buxbaum RE, Mankuta D. Spontaneous first trimester miscarriage rates per woman among parous women with 1 or more pregnancies of 24 weeks or more. 2017;1-7.

5. United Nations. World Fertility and Family Planning 2020 Ten key messages. Dep Econ Soc Aff [Internet]. 2020;(January):2019-20. Available from: https://www.un.org/en/development/desa/population/publications/pdf/family/Ten_key_messages for WFFP2020_highlights.pdf

6. MacQuarrie KLD, Juan C, Allen C, Zweimueller S, Gemmill A. Women's contraceptive profiles throughout the life course in Burundi and Nepal. DHS Anal Stud [Internet]. 2018;(72):xiii-pp. Available from: https://dhsprogram.com/pubs/pdf/AS72/AS72.pdf

7. Maggwa BN, Office AR. F am ily He alth. 2008;2(1).

8. Corker CR and J. 则畈 HHS Public Access. Physiol Behav. 2019;176(3):139-48.

9. Godfrey EM, Chin NP, Fielding SL, Fiscella K, Dozier A. Contraceptive methods and use by women aged 35 and over: A qualitative study of perspectives. 2011 [cited 2021 Jul 21]; Available from: http://www.biomedcentral.com/1472-6874/11/5

10. Staveteig S. Understanding unmet need in Ghana: Results from a follow-up study to the 2014 Ghana Demographic and Health Survey . DHS Qual Res Stud No 20 [Internet]. 2016;(January). Available from: http://dhsprogram.com/pubs/pdf/QRS20/QRS20.pdf 
11. Ghana Statistical Service - GSS, GHS, and ICF International. 2015. Ghana DHS 2014. Rockville, Maryland, USA: GSS, GHS, 2014..12. Aviisah PA, Dery S, Atsu BK, Yawson A, Alotaibi RM, Rezk HR, et al. Modern contraceptive use among women of reproductive age in Ghana: Analysis of the 20032014 Ghana Demographic and Health Surveys. BMC Womens Health. 2018;18(1):1-10.

12. Beson P, Appiah R, Adomah-Afari A. Modern contraceptive use among reproductive-aged women in Ghana: Prevalence, predictors, and policy implications. BMC Womens Health. 2018;18(1):1-8.

13. Asiedu A, Asare BYA, Dwumfour-Asare B, Baafi D, Adam AR, Aryee SE, et al. Determinants of modern contraceptive use: A cross-sectional study among market women in the Ashiaman Municipality of Ghana. Int J Africa Nurs Sci [Internet]. 2020;12(December 2019):100184. Available from: https://doi.org/10.1016/j.ijans.2019.100184

14. Westoff CF, Ochoa LH. Comparative Studies 5: Unmet Need and the Demand for Family Planning [Internet]. g. Institute for Resource Development; Columbia. 1991. Available from: https://dhsprogram.com/pubs/pdf/CS5/CS5.pdf

15. UNFPA. Global Goals Indicators 5.6.1. Research on factors that determine women's ability to make decisions about sexual and reproductive health and rights. 2019;/(October).

16. Vouking MZ, Evina CD, Tadenfok CN. Male involvement in family planning decision making in subSaharan Africa- what the evidence suggests. Pan Afr Med J. 2014;19:1-5.

17. Adongo PB, Tapsoba P, Phillips JF, Tabong PTN, Stone A, Kuffour E, et al. The role of communitybased health planning and services strategy in involving males in the provision of family planning services: A qualitative study in Southern Ghana. Reprod Health. 2013;10(1):1-15.

18. Preissle J. Subjectivity statement. SAGE Encycl Qual Res Methods. 2008;289-92.

19. Braun V, Clarke V. Qualitative Research in Psychology Using thematic analysis in psychology Using thematic analysis in psychology. Qual Res Psychol [Internet]. 2006;3(2):77-101. Available from: http://www.tandfonline.com/action/journallnformation?

journalCode=uqrp20\%5Cnhttp://www.tandfonline.com/action/journallnformation? journalCode=uqrp20

20. Hall KS. The Health Belief Model Can Guide Modern Contraceptive Behavior Research and Practice. J Midwifery Women's Heal. 2012;57(1):74-81.

21. Heath $\mathrm{H}$, Cowley S. Developing a grounded theory approach: A comparison of Glaser and Strauss. Int J Nurs Stud. 2004;41(2):141-50.

22. Wuni C, Turpin CA, Dassah ET. Determinants of contraceptive use and future contraceptive intentions of women attending child welfare clinics in urban Ghana. BMC Public Health. 2017;18(1):1-8.

23. Solanke BL, Banjo OO, Oyinloye BO, Asa SS. Maternal grand multiparity and intention to use modern contraceptives in Nigeria. BMC Public Health. 2018;18(1):1-15.

24. Ajayi Al, Adeniyi OV, Akpan W. Use of traditional and modern contraceptives among childbearing women: Findings from a mixed methods study in two southwestern Nigerian states. BMC Public Health. 2018;18(1):1-9. 
25. Irani L, Speizer IS, Fotso JC. Relationship characteristics and contraceptive use among couples in urban Kenya. Int Perspect Sex Reprod Health. 2014;40(1):11-20.

26. Guure C, Maya ET, Dery S, Da-Costa Vrom B, Alotaibi RM, Rezk HR, et al. Factors influencing unmet need for family planning among Ghanaian married/union women: A multinomial mixed effects logistic regression modelling approach. Arch Public Heal. 2019;77(1):1-12.

27. Kassa M, Abajobir AA, Gedefaw M. Level of male involvement and associated factors in family planning services utilization among married men in Debremarkos town, Northwest Ethiopia. BMC Int Health Hum Rights. 2014;14(1):1-8.

28. Asa SS, Titilayo A, Kupoluyi JA. Assessment of Contraceptive Use by Marriage Type Among Sexually Active Men in Nigeria. Int Q Community Health Educ. 2018;38(3):181-94.

29. Assefa L, Shasho Z, Kasaye HK, Tesa E, Turi E, Fekadu G. Men's involvement in family planning service utilization among married men in Kondala district, western Ethiopia: a community-based comparative cross-sectional study. Contracept Reprod Med. 2021;6(1):1-16.

30. Keogh SC, Otupiri E, Castillo PW, Chiu DW, Polis CB, Nakua EK, et al. Hormonal contraceptive use in Ghana: The role of method attributes and side effects in method choice and continuation. Contraception [Internet]. 2021;(xxxx). Available from: https://doi.org/10.1016/j.contraception.2021.05.004

31. Schrumpf LA, Stephens MJ, Nsarko NE, Akosah E, Baumgartner JN, Ohemeng-Dapaah S, et al. Side effect concerns and their impact on women's uptake of modern family planning methods in rural Ghana: A mixed methods study. BMC Womens Health. 2020;20(1):1-8.

32. Beson P, Appiah R, Adomah-Afari A. Modern contraceptive use among reproductive-aged women in Ghana: Prevalence, predictors, and policy implications. BMC Womens Health. 2018;18(1):1-8.

33. Rominski SD, SKMorhe E, Maya E, Manu A, Dalton VK. Comparing women's contraceptive preferences with their choices in 5 urban family planning clinics in Ghana. Glob Heal Sci Pract. 2017;5(1):65-74.

34. Dali GLA, Pappoe ANM, Akotoye HK. Plants used as abortifacients and contraceptives in some communities on the fringes of subri river forest reserve in Ghana. Afr J Reprod Health. 2019;23(4):92-8.

35. Kleinman A, Eisenberg L, Good B. Culture, Illness, and Care: Clinical Lessons From Anthropologic and Cross-Cultural Research. Focus (Madison). 2006;4(1):140-9.

36. Tilahun T, Coene G, Luchters S, Kassahun W, Leye E, Temmerman M, et al. Family Planning Knowledge, Attitude and Practice among Married Couples in Jimma Zone, Ethiopia. PLoS One. 2013;8(4):1-8.

37. Kabagenyi A, Jennings L, Reid A, Nalwadda G, Ntozi J, Atuyambe L. Barriers to male involvement in contraceptive uptake and reproductive health services: A qualitative study of men and women's perceptions in two rural districts in Uganda. Reprod Health. 2014;11(1):1-9.

\section{Figures}




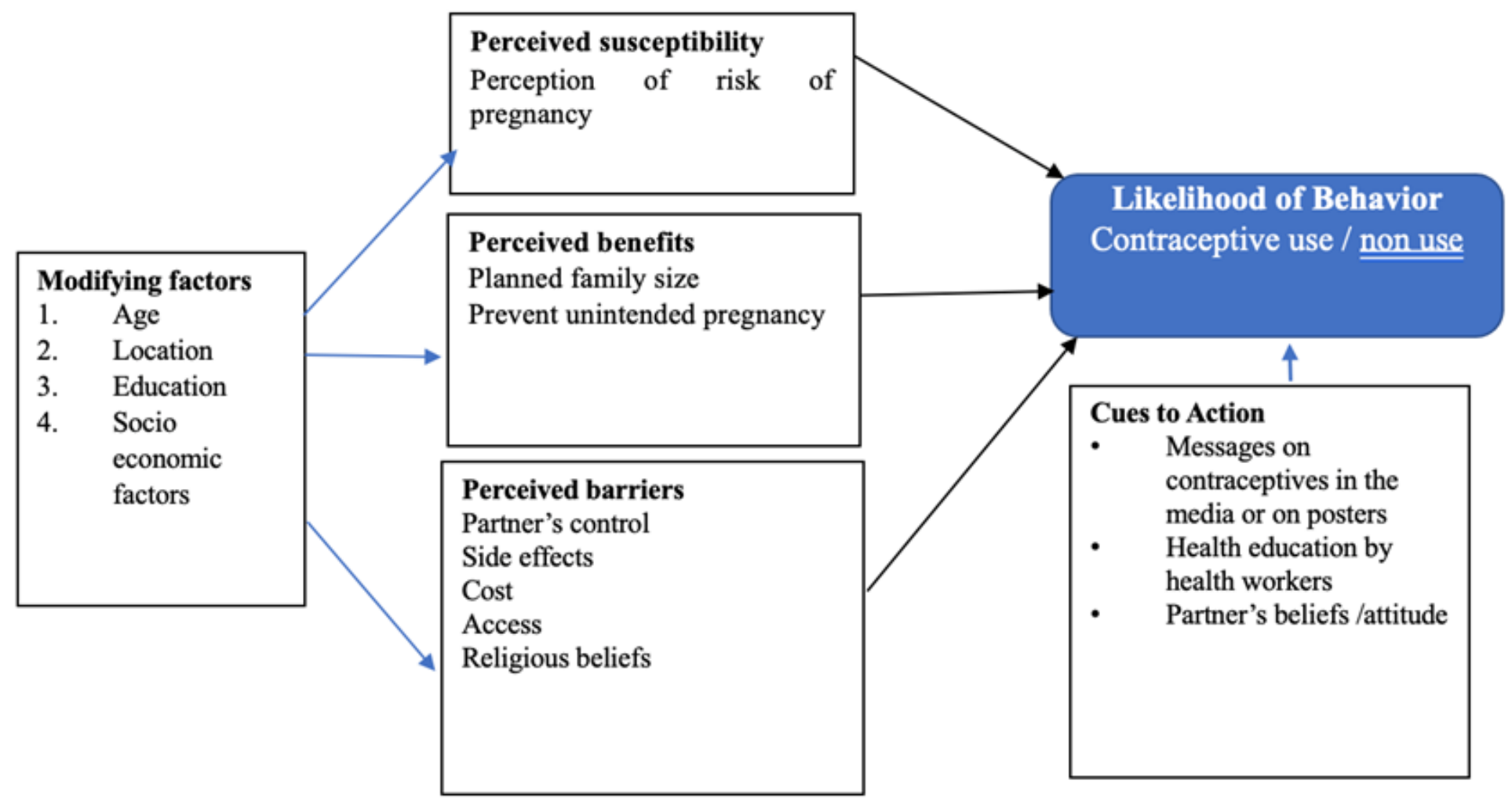

Figure 1

Conceptual framework: Factors that influence modern contraceptive use. 